FOREWORD

\title{
Overview of the "First New Horizons in Medical Laser Applications Symposium” School of Medicine, Keio University
}

\author{
Marvin P Fried \\ General Director, Harvard Medical Laser Center, Boston, MA, USA
}

(Reccived for publication on August 24, 1993)

Key words: lasers, laser-surgery

On Monday, June 21st, 1993, the first joint venture between Keio Medical Association and the Harvard Medical Laser Center was held at Keio University in Tokyo, Japan. This was entitled "New Horizons in Medical Laser Applications". The credit for beginning the process of joining the faculties of the School of Medicine, Keio University and Harvard University School of Medicine interested in laser applications rests with Dr Kenjiro Yasuda. Dr Yasuda was Dean of Keio University, School of Medicine at the time of his trip to Boston in April, 1991 and raised the possibility of such a joint venture. Since then, correspondence between the institutions has been continuous with personal contact highlighted by Dr Toshio Ohshiro's visit to the United States in 1992 as a speaker at the American Academy of Otolaryngology - Head and Neck Surgery Cherry Blossom Conference on Lasers in Washington, DC, and as a visitor thereafter at the Harvard Medical Laser Center Multi-Disciplinary Symposium in Boston. Professor Toyomi Fujino, as President of the Keio Medical Laser Association and Dr Kenjiro Yasuda as Dean of Keio University School of Medicine have enabled the joint venture to reach fruition.

Four Harvard faculty members were invited to present their perspectives on the unique applications of lasers in their own medical specialties. Dr George S Abela, Associate Professor of Medicine and on the staff at the New England Deaconess Hospital discussed "Innovations in Laser Applications in the Cardiovascular Field" $\mathrm{He}$ addressed the effects of the reduction of shock waves during laser angioplasty, as well as progress in the area of direct myocardial reperfusion and electrophysiological applications. His talk was highlighted by some of the critical work done in his own laboratory.

Jeffrey S Dover, MD discussed "What's New in Cutaneous Laser Surgery". Dr Dover is Assisant Professor of Dermatology and Chief of the Dermatology Service at the New England Deaconess Hospital. Dr Dover reviewed the newest concepts in pulsed laser treatment of benign vascular lesions, therapy of epidermal and dermal pigmented lesions, the use of the laser as a surgical scalpel and applications in photodynamic therapy. Advances in the development of diode lasers were discussed, as was the use of lasers for chemical and physical spectroscopic analysis.

Dr Peter McLaren Black, Chief of Neurosurgery at the Brigham and Women's and Children's Hospital and Professor of Neurosurgery discussed the vaporization of solid neoplastic tissue, selective energy absorption with photosensitive dyes, as well as tissue welding. $\mathrm{He}$ highlighted the use of the lasers coupled with imageguided surgery currently being investigated at the Brigham and Women's Hospital.

Marvin P Fried, Director of the Harvard Medical Laser Center, Associate Professor of Otology and Laryngology and on the staffs of the Beth Israel and Brigham and Women's Hospital presented advances in lasers in the field of otolaryngology. The current modification of multiple wavelength usages in rhinology, laryngology and broncho-esophagology were discussed, particularly in regard to their limitations and possible risks. Dr Fried also described in detail his work on combining rapid MR imaging with interstitial laser photocoagulation of solid tumors, done in conjunction with Dr Ferenc Jolesz of the Department of Radiology at the Brigham and Women's Hospital.

It was apparent to all those interested in the use of lasers in medicine that these devices have a role in almost every specialty and joints physicians and their associates with a common purpose. The founding of the Keio Medical Laser Association and the Harvard Medical Laser Center has been in response to the need for opening up avenues of exchange so that all can benefit from their collective experiences. Each of these organizations attempts to reach these goals within their own communities. It was hoped that not only can we learn from each other but also promote the stimulation and dissemination of ideas, teaching methodology and collaborative research between our institutions.

Reprint requests to: Dr Marvin P Fried, Associate Professor of Otology and Laryngology, Harvard Medical School: General Director. Harvard Medical Laser Center, 333 Longwood Avenue, MA 02115, USA 